Religare, ISSN: 19826605, v.16, n.1, agosto de 2019, p.57-84.

\title{
Uma coalização de defesa, na busca de um embrião de Estado Neopentecostal
}

\author{
A defense coalition in search of a Neopentecostal state \\ embryo
}

\author{
Nelton Moreira Souza ${ }^{1}$ \\ Eliete Barbosa de Brito Silva ${ }^{2}$ \\ Patricia Rodrigues Chaves da Cunha ${ }^{3}$
}

\section{Resumo}

Este artigo apresenta uma análise das práticas políticas de parlamentares pentecostais e neopentecostais da Assembléia de Deus e Igreja Universal do Reino de Deus no Congresso da República do Brasil. Compara essas práticas pentecostais e neopentecostais com padrões de comportamento da cultura política brasileira e as ações correspondentes do Estado nacional como

\footnotetext{
${ }^{1}$ Doutorado em andamento na Área de Ciência Política Pelo Programa de Pós-graduação em Ciência Política do Instituto de Filosofia; Sociologia e Política, na linha de Pesquisa Processos Políticos: Atores e Instituições, pela Universidade Federal de Pelotas, IFISP /UFPEL. Mestrado em Geografia Pelo Programa de Pós-graduação em Geografia do Instituto de Estudos Socioambientais, na linha de pesquisa Dinâmica Socioespacial IESA /UFG; Especialista em Docência do Ensino Superior, pela Faculdade Brasileira de Educação e Cultura; Graduação em Geografia pelo IESA/UFG; Formação complementar em Atores, Sujeitos e Agentes da Cultura Popular - IPHAN; Curso de Aperfeiçoamento em Ciência Política sob a Supervisão Prof. Dr. Clóvis de Barros Filhos, pela Universidade de São Paulo (USP). Professor e Pesquisador com atuação em organizações da Sociedade Civil: Membro do Conselho Nacional de Política Cultural - CNPC/MINC; Membro do Comitê Intersetorial da Política Municipal para População em Situação de Rua; Consultor Técnico Plano de Direitos Humanos da Prefeitura Municipal de Goiânia; Membro da Comissão Estadual da Memória; Verdade e Justiça Dep. Jose Porfírio de Souza SDH/CEMVJ; Membro do Coletivo de Empreendedores Afro-Brasileiros do Estado de Goiás.

2 Doutoranda em História na Universidade Federal de Goiás. Mestre em História pela Universidade Federal de Goiás. Especialista em História do Brasil pela Universidade Federal de Goiás (2004). Graduada em História pela Faculdade do Noroeste de Minas (1998). Atualmente é professora de História nas séries finais do Ensino Fundamental - Secretaria Municipal de Educação de Valparaíso de Goiás. Tem experiência na área de História, com ênfase em História Geral. Desenvolve pesquisas abordando as temáticas: Mobilidade Social, Segregação Socioespacial, Processo de construção de identidades, Relações de gênero e Análise de discurso.

${ }^{3}$ Graduação em Ciências Sociais pela Universidade de São Paulo (1996), mestrado em Ciência Política pela Universidade Federal do Rio Grande do Sul (2005) e doutorado em Ciência Política pela Universidade Federal do Rio Grande do Sul (2011). Atualmente é adjunta da Universidade Federal de Pelotas e professora do Programa de Pós-Graduação em Ciência Política. Coordenadora do Grupo de Pesquisa Democracia e Políticas Públicas. Tem experiência na área de Ciência Política, com ênfase em Cultura Política, atuando principalmente nos seguintes temas: juventude, políticas públicas, participação política, democracia e cidadania.
} 
preservador dessa mesma cultura. Intercalando-se a analise com alguns traços do Trade Policy-Making a partir das inter-relações que se estabelecem entre Estado e Religião na forma de Coalizões de Defesa, na busca de um embrião de Estado neopentecostal. A abordagem aqui proposta não é histórica, nem linear, recorre à história social e suas interfaces com os processos políticos que se manifestam no trade policy-makin. $\mathrm{O}$ artigo se propõe a lançar luz sobre alguns pontos da complexa inter-relação entre atores estatais e sociais e suas funções e negociações na consecução da agenda política. O referencial teórico mobilizado é o Advocacy Coalition Framezwork. Com o intuito de compreender as relações, entre Estado, Política e Religião, na atual democracia brasileira, recorreu-se ao método comparativo. Considerando que as articulações arquitetadas pela bancada evangélica, no legislativo brasileiro, tem sido marcadas por um forte tradicionalismo moral da Frente Parlamentar Evangélica, que tem a missão de atuação na defesa da família e da moral cristã, sendo contra a plataforma dos movimentos feministas; da identidade de gênero, dos homossexuais e dos grupos de direitos humanos, valendo-se de alianças até mesmo com parlamentares católicos, fomentando um discurso moralístico, anticorrupção cabe-nos inquirir acerca dos objetivos implícitos na ação da bancada evangélica. Onde se esconde o seu pote de ouro?

Palavras-Chave: Estado; Politica; Religião; Coalizão de Defesa; Poder Legislativo.

\section{Abstract}

This article presents an analysis of the political practices of Pentecostal and neoPentecostal of Parliamentary Assembly of God and Universal Church of the Kingdom of God in the Congress of the Republic of Brazil. Compares these Pentecostal and neo-Pentecostal practices with patterns of behavior of the brazilian political culture and the corresponding actions of the national State as a preserver of this same culture. Merging-if the analysis with some traces of the trade policy-making from the interrelations established between State and Religion in the form of Coalitions of Defense, in search of an embryo neopentecostal of Brazilian State. The approach proposed here is not historic, nor linear, refers to the social history and its interfaces with the political processes. That you/they show in the trade policy-making, the article intends to throw light on some points of the complex interrelation among state and social actors and their functions and negotiations in the attainment of the political calendar. The mobilized theoretical referencial is the advocacy coalition framework. With the intention of understanding the relationships, among State, 
Religare, ISSN: 19826605, v.16, n.1, agosto de 2019, p.57-84.

Politics and Religion, in the current Brazilian democracy, it was fallen back upon the comparative method. Considering that the articulations built by the evangelical bench, in the Brazilian legislative, it has been marked by a fort front moral traditionalism Parliamentary Evangelical, that he/she has the mission of performance in the defense of the family and of the Christian morals, being against the platform of the feminist movements; of the gender identity, of the homosexuals and of the groups of human rights, being been worth of alliances even with Catholic parliamentarians, fomenting a speech moralístico, anticorrupção fits to inquire us concerning the implicit objectives in the action of the evangelical bench. Where does he/she hide his/her pot of gold?

Keywords: State; Politics; Religion; Coalition of Defense; Legislative Power.

A abordagem aqui proposta não é histórica, nem linear, porém recorre à história social, e suas interfaces com os processos políticos, que se manifestam no Trade Policy-Making, o artigo se propõe a lançar luz sobre alguns pontos da complexa inter-relação entre atores estatais e sociais (Estado/Região) e suas funções e negociações na consecução da agenda política. Portanto, o referencial teórico mobilizado é o advocacy coalition framework (coalizões de defesa), que aporta uma leitura atinente à transversalidade da problemática em foco, que implica múltiplos atores e conflitos em torno de objetivos, metas e mecanismos da ação pública, com o intuito de compreender as relações, entre Estado, Política e Religião, na atual democracia brasileira, recorreu-se ao método comparativo, para elucidar as singularidades da sociedade brasileira e as relações entre atores supracitados. De tal modo, destacamos às passagens primordiais do pentecostalismo para o neopentecostalismo na sociedade brasileira com o intuito de identificar a cultura política que aqui foi gerada.

Estudiosos, tais como Bernardo Sorj, Joanildo Burity, Marcelo Baquero e Paulo Henrique Martins, têm concordado que não é possível aproximar-se de uma sociedade tão complexa como a nossa, com o intuito de compreendê-la, 
Religare, ISSN: 19826605, v.16, n.1, agosto de 2019, p.57-84.

elegendo um ou outro fator estruturante, entretanto os estudos que tratam das questões supracitadas, em relação ao entendimento da realidade brasileira, têm despertado especial interesse no meio acadêmico. Deste modo, Bernardo Sorj, nos salienta que, as análises sociológicas que privilegiavam, ou elencavam um único fator, para compreender a organização social e suas contradições não se manifestaram de forma satisfatória.

Assim, uma variante dessa abordagem, o pensamento estruturalista, por exemplo, restringe o social a dicotomias, em sacrifício da multiplicidade de fatores que o constituem. O emprego de paradigmas simplistas e as abordagens monocausais proporcionaram a ilusão de um mundo social coerente, racional, regido por uma lógica única, ou seja, a Ciência Social construída nestes moldes contribuíram para produzir visões inflexíveis da sociedade. Portanto, com uma perspectiva mais pluralista, a realidade brasileira demanda de fatores múltiplos, que nos possibilita dar inteligibilidade a seus processos de desenvolvimento. (BAPTISTA, 2007).

A partir deste panorama exploratório, busca-se, em um primeiro lugar, arrolar padrões culturais da formação histórico-social brasileira. Em seguida, procede-se à identificação de práticas sociais e políticas dos pentecostais e neopentecostais, na literatura existente, a fim de comparar esta inter-relação religiosa com o contexto social político no qual está inscrita. Portanto, recorremos à secularização do aparato jurídico-político, que constitui os procedimentos históricos decisivo na formação das sociedades modernas ocidentais.

No caso da sociedade brasileira, constata-se que, a separação entre o Estado-Igreja, ocorre concomitantemente com o advento do regime republicano, 
Religare, ISSN: 19826605, v.16, n.1, agosto de 2019, p.57-84.

não só faz parte desse processo de secularização ${ }^{4}$ como o impulsiona. A separação entre Igreja (Religião) do Estado, possibilitou a este autonomia em relação ao grupo religioso ao qual se aliava, ampliando a sua dominação jurídica e política sobre as esferas religiosas, ou seja, a secularização dos aparatos, jurídico-político, proferiu a autonomia e supremacia do direito em relação às outras formas de ordens normativas, minimizando as pretensões dos grupos religiosos em impor suas normas ao conjunto da sociedade, submetendo-as ao rigor da lei, relativizando, e relegando-as ao segundo plano e desqualificando as demais fontes de normatividade. (MARIANO, 1999).

De tal modo, que esta separação, deveria ter contribuído efetivamente para a diversificação institucional do campo de poder, ao decretar o fim do monopólio religioso, bem como a garantia da liberdade e do pluralismo de crenças. Entretanto, na sociedade brasileira, pluralista, veio a consolidar-se-tãosomente na segunda metade $X X$, ou seja, mais de meio século após a separação entre Igreja-Estado, tal processo tardio emergiu-se conectado a lógica de mercado, a qual passou a orientar as ações organizacionais, religiosas e proselitistas de vários grupos religiosos, sobretudo de certas denominações pentecostais e neopentecostais.

De tal modo, que a pressão exercida pelo mercado influenciou os rumos do neopentecostalismo, observa-se que diversas igrejas desse movimento religioso, esta estruturada em um modelo de organização e gestão empresarial (institucional, organizacional, teológico e mercadológico), cujo efeito é acentuar a concentração e verticalização do poder eclesiásticas e bem como a centralização administrativa, financeira e política (MARIANO, 1999). O perfil

\footnotetext{
${ }^{4}$ Flávio Pierucci (1998) mostra que o conceito weberiano de secularização envolve, acima de tudo, o longo processo de racionalização ocidental da ordem jurídico-política, o disestablishment ou a separação da religião do Estado, que, na modernidade, se torna laico, domínio da lei e guardião do direito formal. Direito que, nesse contexto, por ser dessacralizado, se torna legitimamente revisável.
} 
Religare, ISSN: 19826605, v.16, n.1, agosto de 2019, p.57-84.

do líder pentecostal bem-sucedido, esta cada vez mais conectada ao de um empresário ou administrador de empresas. Fatos que convergem com a fala do Bispo Edir Macedo - ao considerar que "o dinheiro é uma ferramenta sagrada usada na obra de Deus" e, ou seja, em uma analogia biológica, o "sangue da Igreja" (MACEDO, 2000, p. 52); (1986 p. 97).

Constata-se no plano jurídico, uma separação entre Estado e Igreja, entretanto, quando nos debruçamos na compreensão deste rizoma social, pelo viés da formulação de políticas públicas, constam-se ambíguas relações e ranços históricos e imbricações na práxis da política. Datadas anteriores ao período de redemocratização brasileira, conforme nos salienta, Benjamin Arthur Cowan (2014).

Em 1979, o Brasil avançou em direção à democracia. Dr. Eli Francioni de Abreu, o diácono da Primeira Igreja Batista de Niterói de Nilson Fanini, afirmou que nem tudo estava bem no mundo. "Os dias em que estamos vivendo", ele escreveu, bem poderiam ser caracterizados pela palavra insatisfação. De todas as partes do globo ouvimos de nações com os variados problemas. Revoltas, protestos, roubos, assaltos, crimes de toda a sorte [...]. A moral desce tão baixa pelo desfiladeiro da degenerescência. À sociedade moderna, tão materializada e corrompida, faltam as duas coordenadas [...] que governam toda a conduta do homem no Universo, Abreu compartilhava com seu pastor, o próprio Fanini - uma estrela nascente naquele período -, este sentimento de crise aguda [...] Quase uma década depois, enquanto Edir Macedo, fundador e líder da Igreja Universal do Reino de Deus, tornava-se um nome familiar no Brasil, a mensagem de Fanini e de Francioni saiu do púlpito e entrou nas salas de poder do estado transicional. A Assembleia Nacional Constituinte (ANC) reuniu-se em Brasília para debater e codificar as promessas democráticas feitas na década de 1970 e um quadro emergente de políticos evangélicos preparava as bases para o que viria a ser conhecido como a bancada evangélica, um bloco evangélico ideologicamente congruente no legislativo nacional. (COWAN, 2014, p 4). 
Religare, ISSN: 19826605, v.16, n.1, agosto de 2019, p.57-84.

Em 2016, essas confissões podem soar familiares para uma população acostumada como discursos e com estreitas políticas evangélicas de um Silas Malafaia; Marco Feliciano; Eduardo Cunha ou Jair Bolsonaro. Mais recentemente, o poder legislativo tem sido permeável à ascendência desta bancada evangélica, denominada Frente Parlamentar Evangélica, que atualmente fazem coalizões de defesas com Frentes Parlamentar da Família e Apoio a Vida, que conta com cerca 165 Deputados em exercício do mandato, 37 Deputados Signatários e 26 Senadores (Câmara dos Deputados, 2016).

Entretanto, vale ressaltar que no Brasil desde 1998, ouve o florescer das vertentes conservadoras no cenário político evangélico, sendo que não era uma consequência previsível. Pois esses atores historicamente estavam autodeclarados apolíticos.

Os evangélicos no Brasil primeiramente evitaram qualquer envolvimento com o ambiente "mundano", porém a partir do momento em que o país começou a abrir-se para a reconstrução das suas instituições democráticas, os atores protestantes de várias designações começaram a eclodir na cena política ${ }^{5}$. Vários especialistas do fenômeno evangélico na política brasileira demarcam a década de 1980, como marco temporal desta fase de politização que aglutinou uma variedade de tendências, estre estas se destacaram o progressismo e protestante $^{6} .($ COWAN, 2014).

De tal modo, que parte significativa dos evangélicos do Brasil, urdiu uma Nova Direita, que esta fortemente atrelada com o momento histórico, que datase em torno de uma década, em que os evangélicos emergiram na esfera

\footnotetext{
${ }^{5}$ GUIMARÃES, Larissa; FALCÃO, Márcia. Bancada evangélica diz que não vota 'nada' até esclarecer 'kit gay'. Folha de São Paulo, 2011; CASTRO, Gabriel; MATTOS, Marcela. Vinde a mim os eleitores. Veja, 03/2013.

${ }^{6}$ CAMPOS, Leonildo Silveira. Os políticos de Cristo; LÖWY, Michael. The war of Gods: religion and politics in Latin America. London/New York: Verso, 1996; SILVA, Paulo Julião da. O alinhamento protestante ao Golpe Militar e a repressão aos 'crentes subversivos'. Historia e Debate, 24/03/2010.
} 
Religare, ISSN: 19826605, v.16, n.1, agosto de 2019, p.57-84.

política-administrativa em especial nos setores públicos e privados da sociedade brasileira, é notório o fato de que estas vertentes conservadoras, de base moralista avançaram rapidamente em direção ao terreno fértil do poder legislativo, e atualmente, Judiciário e Executivo. Portanto, nas sociedades ditas democráticas, “a esfera pública é o espaço político em que se dá a passagem da vontade individual para à vontade coletiva, o lugar onde os indivíduos negociam seus interesses pessoais e suas representações do bem comum"7 .

Entretanto, na formação histórica do desenvolvimento da sociedade brasileira, nota-se a prática de um processo de autodestruição do limite do que é publico, mediante a expansão do privado ${ }^{8}$. (BAPTISTA; 2007). De tal modo, que o ethos público, segundo Gabriel Cohn, é "um modo de orientação das condutas, das percepções, dos modos de pensar e agir enfim, [referenciado] ao complexo de valores que regem a conduta no mundo social e político nas suas relações com o mundo privado ${ }^{\prime \prime}$. Assim, podemos inferir que a inserção dos atores pentecostais/neopentecostais na dinâmica política, influenciou e influencia na formulação de determinadas políticas públicas, ou seja, o reconhecimento de que outros segmentos que não só, os governos se envolvem na formulação de políticas públicas, tais como, os grupos de interesse e os movimentos sociais, cada qual com maior ou menor influência, em relação ao tipo de política a ser formulada e das coalizões que integram a estrutura de governo. (PETERS, 1998).

De acordo com Paul Freston (1992) ${ }^{10}$ a crescente inserção dos pentecostais na política brasileira, se faz em decorrência da capacidade de organização e

\footnotetext{
7 SORJ, Bernardo. A democracia inesperada: cidadania, direitos humanos e desigualdade social. Rio de Janeiro: Jorge Zahar, 2004, p. 24.

${ }^{8}$ GURZA LAVALLE, Adrián. Vida pública e identidade nacional: leituras brasileiras. São Paulo: Globo, 2004, p.12.

9 Idem, p.12.

${ }^{10}$ FRESTON, Paul. Evangélicos na política brasileira. Religião e Sociedade, Rio de Janeiro: ISER, no 16/1 2, 1992,
} 
Religare, ISSN: 19826605, v.16, n.1, agosto de 2019, p.57-84.

mobilização que acumularam para defender, principalmente, seus interesses corporativos, mostrar-se também os diferentes matizes da atuação dos evangélicos em geral nesse mesmo contexto. (BAPTISTA, 2007). Neste sentido, Theodor Lowi (1964; 1972) desenvolveu a mais difundida tipologia sobre política pública, que consiste na máxima: "a política pública faz a política". Com essa máxima Lowi quis nos dizer que cada formulação de política pública ira encontrar diferentes formas de adesão e de rejeição em disputas emersas a sua decisão, que perpassam por arenas diferenciadas.

Assim, a política pública, pode assumir quatro formas, sendo a primeira a das políticas distributivas, onde a tomada de decisão perpassa pelo governo, $\mathrm{o}$ qual desconsidera a relação dos recursos limitados, tal tipologia, acarreta impactos mais individuais do que universais, a priorizar grupos e atores sociais ou localidades em detrimento do todo. Ou seja, este modelo privilegia o favorecimento do patrimonialismo, por exemplo, as políticas redistributivas. Já, o segundo modelo/tipologia é o das políticas regulatórias, que são mais notórias ao público, envolvendo uma maior burocracia, bem como atores políticos e grupos de interesse de várias agremiações.

O terceiro consiste nas políticas redistributivas, o qual atinge maior número de pessoas, impondo perdas concretas em curto prazo para determinados grupos sociais e ganhos incertos e futuros para outros; são normalmente políticas universais, tributárias, previdenciárias e são as mais difíceis de encaminhamento, pois envolvem vários atores e interesses, bem como diversas arenas. Já o quarto é o das Políticas consultivas, que articulam com os demais procedimentos. Assim, cada uma dessas tipologias de política pública, vai gerar apoio de determinados atores e vetos de outros, porém ambos se interagem dentro do sistema político administrativo, de forma diferente, seja pelas articulações e bases de coalizões distintas. De tal modo, que Paul Freston 
Religare, ISSN: 19826605, v.16, n.1, agosto de 2019, p.57-84.

(1993), em sua tese doutorado, empenhou-se. Na análise das “tipologias do protestantismo e pentecostalismo fazendo uma análise institucional das denominações, com ênfase na cultura e estratégia políticas procedendo-se a comparação entre elas nos mesmos aspectos", o autor nos salienta que a vertente do neopentecostalismo tem cosmovisão aguerrida, que se expressa, também, no cenário político. Assim apoiando neste panorama exploratório adentramos as ambíguas relações existentes entre o Estado e os atores religiosos e suas influências no cenário político brasileiro.

\section{A Secularização do Estado e a Constituição do Campo Religioso e suas influências no cenário político}

O processo de secularização concebeu o Estado brasileiro, como o único e conseguintemente legítimo mediador das relações entre as agremiações religiosas ou religiões no país. Tal atribuição se consolidou por intermédio do decreto de 119A, de 07 de Setembro de 1890, sancionado pelo então, Governo Provisório da República dos Estados Unidos do Brasil, de autoria do vice-chefe do governo Rui Barbosa, tal decreto, proibia autoridades e órgãos públicos de expedir leis, regulamentos ou atos administrativos que pusessem a religião ou a vedassem, constituindo-se plena liberdade de culto e religião para todos os indivíduos, igrejas e agremiações religiosas etc. (GRUMAN, 2005). Vinculada, a constituição de 1891, a então separação da igreja católica do Estado se fez garantir a plena liberdade religiosa e de culto para todos os indivíduos, proporcionando no transcorrer do século XX, a fundação do Estado moderno e à acessão de um mercado aberto na cena religiosa brasileira. Abrindo-se prerrogativas para que, anos mais tarde viesse a colocar a prova, o poderio hegemônico do catolicismo em contraposição ao proselitismo das novas vertentes e tendências. (BAPTISTA, 2007; FRESTON, 1993; GRUMAN, 2005). 
Religare, ISSN: 19826605, v.16, n.1, agosto de 2019, p.57-84.

Portanto, é de extrema relevância atentar-se para a consolidação deste campo religioso "genuinamente plural e democrático" bem como o seu reconhecimento pelos diversos atores sociais que o compõem, uma vez, que tal seara é marcada por intensas disputas pelo poder, para definir a corrente detentora de maior legitimidade, ou seja, o tipo de legitimidade conquistada por uma instância religiosa pode invocar-se independe da posição que ocupa num determinado estado de relações, seja estas hegemônicas, ideológicas, políticas etc.

Assim, o desencadear-se da secularização do Estado se fazem em decorrência da pretensa separação entre o que se pensa, e o que faz no espaço público, em contraposição as relações no espaço privado, a priore, ideologia expressa na primeira sentença, exigiria dos indivíduos o respeito às leis impessoais e universais, independente de avaliações e filiações de pertencimento a identidade/grupo em particular, enquanto na segunda trás a prerrogativa de que as relações pessoais se estabeleceriam a partir de critérios morais e exclusivos.

Deste modo, o complexo mundo da política estaria em uma sobreposição ao espaço público, ao passo que a religião ficaria relegada ao espaço privado, das igrejas, mesquitas e sinagogas etc. A pesar de constar-se na constituição de 1891, a separação entre Estado e Igreja, o governo de Getúlio Vargas (1930-1945) reconstruiu uma série de privilégios à Igreja Católica Romana, a exemplo a admissão de padres como capelães militares e a introdução de crucifixos nas repartições da administração pública. (BAPTISTA, 2007; FRESTON, 1993; GRUMAN, 2005).

Assim, na constituição promulgada de 1934, a elite eclesiástica católica restabeleceu certos privilégios em decorrência da sua ambígua relação com o Estado, por exemplo, o casamento religioso foi reconhecido pela lei civil; foram 
Religare, ISSN: 19826605, v.16, n.1, agosto de 2019, p.57-84.

sancionados os direitos a educação religiosa em escolas públicas durante o período de aulas; foi permitido ao estado financiar escolas da igreja, seminários, até hospitais e quaisquer outras atividades tomadas como de interesses coletivo. Em 1997, a influência hegemônica da igreja católica, o chamado "lobby da batina"11 (católico) conseguiu formar uma base de pressão (Coalização de Defesa), que fez com que o então presidente da república, Fernando Henrique Cardoso, retirasse do texto original da Lei de Diretrizes e Bases da Educação (LDB) a declaração sem ônus para os cofres públicos referentes à oferta do ensino religioso nas escolas públicas, prerrogativa mantida da constituição de 1934. (GRUMAN, 2005).

Entretanto, quando analisando os dados do Censo Demográfico de 2000 do Instituto Brasileiro de Geografia e Estática (IBGE) observa-se um declínio institucional da igreja católica, pois se em 1970, 91,8\% da população se autodeclaravam católicos, esse índice apresenta-se em queda para 73,9\% de acordo com o censo 2000. Entretanto, verifica-se um crescimento proporcional e significativo em números absolutos de evangélicos, sejam eles históricos ou pentecostais e posteriormente neopentecostais. Em 1970, somavam 5,2\% da população brasileira, porém este índice triplica num período de trinta anos, alcançando 15,6\% em 2000. Em contraposição aos Dados do Censo 2010, percebe-se que os grupos autodeclarados católicos passaram-se 73,9\% da população no Censo de 2000, para 64,6\% no Censo 2010. Os autodeclarados evangélicos passaram-se 15,6\% no Censo Demográfico de 2000, para 22,2\% em 2010. De acordo com a figura abaixo.

Figura-01: Classificação percentual dos grupos religiosos Censo 2000 em comparação com o Censo 2010.

\footnotetext{
11 [...] Na esteira do "lobby da batina", instrumentaliza sua atuação na esfera pública para reforçar seu desempenho no mercado religioso, e vice-versa (ROMANO, 2000, p.26).
} 
Classificação percentual dos grupos religiosos e comparação com o Censo 2000

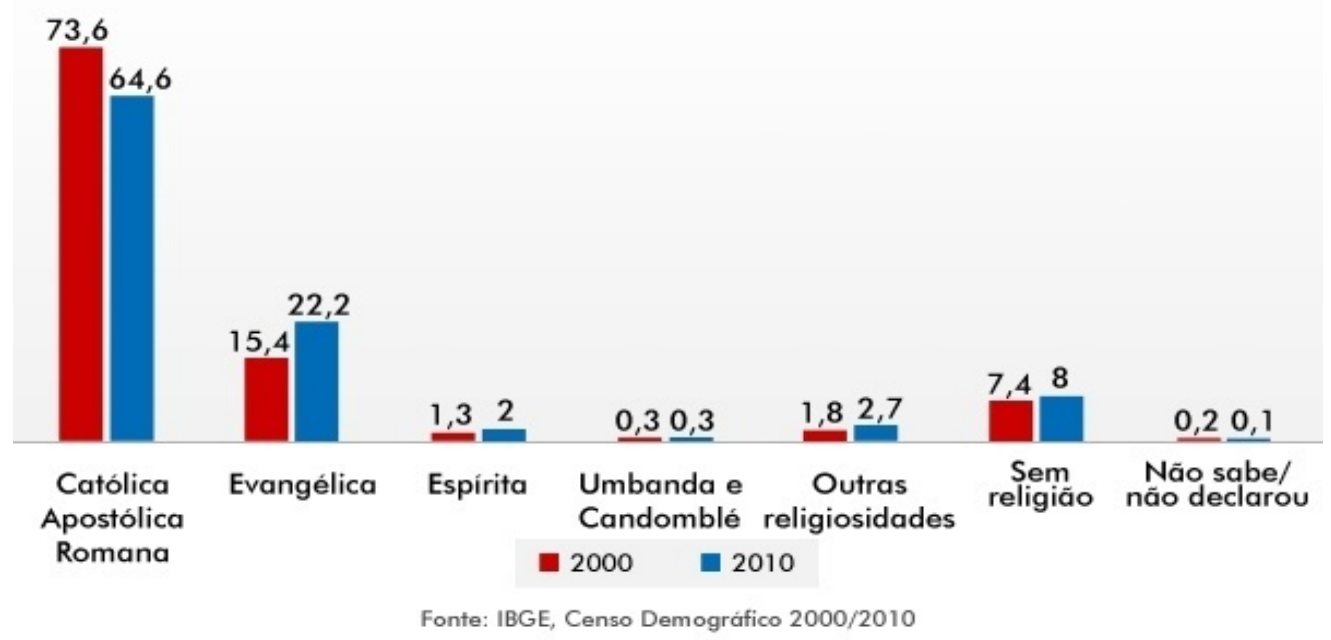

Portanto, é relevante, pontuarmos que no início da década de 90, os evangélicos representavam apenas $9 \%$ do contingente populacional, dos quais a maioria de origem pentecostal, com a expansão das igrejas evangélicas pelo país, em especial o seguimento da Universal do Reino de Deus (neopentecostal), e a veiculação de programas religiosos nas emissoras de televisão e à acessão destes atores nos diversos extratos sociais da população, contribuiu para o aumento deste índice na última década. Por outro lado, essa reestruturação do modo como os evangélicos, em especial os neopentecostais da Igreja Universal do Reino de Deus (IURD), arquitetam a representação política e se relacionam com o espaço público, construindo e alimentam um discurso que se reverbera no contexto do descrédito das políticas tradicionais, e a aversão da política de maneira geral. Tais estratégias fazem parte do jogo político deste seguimento, pois a simbólica diabolização da vida política coloca-se em pauta a necessidade de uma nova moral pública, responsável pelo combate à corrupção, em defesa dos valores da família e o resgate do bem-estar dos cidadãos, tal discurso legítima a inserção de políticos evangélicos, em geral neopentecostais na esfera da administração pública: 
Religare, ISSN: 19826605, v.16, n.1, agosto de 2019, p.57-84.

Para os fiéis iurdianos, votar não constitui apenas um exercício de cidadania [...] Trata-se de um gesto de exorcismo do demônio que se encontra na política e de sua libertação [...] $\mathrm{O}$ gesto de votar adquire o sentido de um rechaço do "mal" presente na política e sua substituição pelo "bem", ou seja, por pessoas convertidas ao evangelho, por "verdadeiros cristãos", "por homens de Deus". [...] A Universal mobiliza na esfera política crenças, valores, símbolos e cosmovisões do seu universo simbólico, e a partir deles produz uma ressemantização do voto, inscrevendo-o "numa lógica cosmológica, na perspectiva da guerra santa." 12 (ORO, 2003 apud GRUMAN, 2005, p.109).

Tal citação nos chama a atenção, para esta Práxis New Polity inaugurada pelos segmentos evangélicos, em especial o neopentecostalismo, alicerçada na adoção de práticas clientelísticas, por grande parte de suas lideranças religiosas, inseridas nos três poderes da república em especial no legislativo brasileiro. Assim a conduta de parlamentares oriundos desse segmento político-religioso, esta em grande parte vinculado a certo corporativismo de viés religioso, impossibilitando seu enquadramento na envergadura ideológico do quadro partidário nacional. O crescimento do capital político seria uma consequência da constituição de uma base, vinculada aos serviços prestados em obras assistencialistas "missões" gerenciadas pela Igreja, numa espécie de "clientelismo corporativo", permitindo aos seus representantes a barganha política de apoio e aliança na construção uma base eleitoral estável (BAPTISTA, 2007; FRESTON, 1993; GRUMAN, 2005). Portanto, as perspectivas supracitadas nos fornecem subsídios para compreendermos, a dinâmica processual do aumento expressivo de representações religiosas na esfera do poder legislativo,

12 A.P. ORO, A política da Igreja Universal e seus reflexos nos campos religioso e político brasileiros. In: Revista Brasileira de Ciências Sociais, vol.18 n.53, outubro/2003; Igreja Universal: um poder político. In: A.P. ORO A. CORTEN \& J-P DOZON (orgs.) Igreja Universal do Reino de Deus: os novos conquistadores da fé, SP: Paulinas, 2003. 
Religare, ISSN: 19826605, v.16, n.1, agosto de 2019, p.57-84.

seja ela, Municipal, Estadual ou Federal; De tal modo, que este novo modo de fazer política desses atores mencionados, baseia-se numa razão instrumental que coloca em segundo plano a natureza simbólica da representação política, conjugando o êxito eleitoral neopentecostal às mazelas materiais recorrentes em suas bases eleitorais.

Assim, em virtude da acessão destes atores religiosos, pentecostais e neopentecostais na esfera pública e conseguintemente o fortalecimento desta bancada no legislativo, que se articulada com um poder de interferência significativo, entre diversos atores e segmentos de interesses, com uma ação orgânica e integrada. Mesmo não apresentando um poder coeso, unificado e totalmente integralizado, e, por isso, torna se um "quebra cabeça" difícil para qualificá-la e caracterizá-la numa perspectiva genérica, uma vez que existem várias dissidências internas.

Porém, com toda essa complexidade, a qual ela esta emersa, é notória a capacidade de formação de bases coalizações que este detém, quando se trata da formulação da agenda política, da prática de políticas públicas que versão sobre os seus interesses ou contradizem, as vertentes por eles defendidas. Nessa arena do campo político, onde se aproxima no bojo da política, a formulação da agenda de política pública, e a política externa e interna é despida do rótulo de política de Estado, isolada nas contingências do sistema político, os interesses nacionais são invocados pelos princípios ordenadores de metas, objetivos e mecanismos da política externa e interna cedendo espaço para uma dinâmica de interesses plurais que disputam espaços no bojo do policy-making. (SILVA, 2014).

De Tal Modo, que a participação cada vez mais acentuada e proativa de atores sociais no debate de ideias, valores e interesses que incidem sobre as escolhas políticas - revela um cenário de disputas entre projetos políticos 
Religare, ISSN: 19826605, v.16, n.1, agosto de 2019, p.57-84.

distintos para o Brasil (MILANI; PINHEIRO, 2013). No contexto, a dimensão cognitiva que está emersa ao conteúdo das políticas públicas não é trivial, seja pelo fato, das crenças, valores e ideias desempenharem o papel de quesitos, de fundamental importância dentro do processo de formulação de qualquer política pública (SILVA, 2014). Portanto, estes quesitos, desenvolvem a tarefa de "calcificar" os vínculos entre os atores que coalizam-se em determinados subcampos ou subsistema de policy.

De tal modo que a transversalidade da problemática em questão, que provoca múltiplos atores (não governamentais e governamentais de diferentes níveis) e conflitos fortemente enraizados em torno dos objetivos, metas e mecanismos da ação pública, sustentasse que o referencial teórico mais apropriado para compreender alguns traços desse cenário complexo e multidimensionado é o advocacy coalition (coalizões de defesa) (SABATIER, 2006). Observa-se, que este modelo estabelece uma adaptação da representação pluralista clássica ao aconselhar que os grupos de interesse, são coalizões de defesas composta por grupos e atores heterogêneos, movidos por interesses comuns, mas também pela defesa de visões políticas tidas como "boas" para a sociedade.

Deste modo, a política pública seria resultado das influências mútuas e dos conflitos, entre coalizões de defesa no interior de cada subsistema de políticas, ou seja, a interação com outros subsistemas. Assim, as ideias e posicionamentos defendidos por uma coalização abrangem representações de três níveis superpostos: (a) deep core, que consiste nos valores, crenças e máximas ontológicas e normativas fundamentais; (b) policy core, indica a existência de um núcleo duro de crenças sobre as políticas públicas e que fornece princípios fundamentais para o subsistema de políticas; (c) Secondary aspects, consiste nas estratégias e ferramentas operacionais de política de caráter 
Religare, ISSN: 19826605, v.16, n.1, agosto de 2019, p.57-84.

mais superficial e secundário que dão suporte ao nível anterior (MARQUES, 2013).

Neste sentido, podem-se estabelecer acordos e compromissos e barganhas entre coalizões, assim atônica das interações estre elas, são intermediadas pelos jogos de interesses: cada qual usa se de artifícios e estratégias para tentar impor suas preferências e realizar seus princípios de ação coerentes com os respectivos sistemas de crenças. Em âmbito geral, cada subsistema de Política Pública, com até quatro coalizões, em via de regra em grande parte das áreas/setores é comum a existência de apenas duas grandes coalizões, dependendo-se do teor da política e suas áreas de atuação, pode emerge uma única coalizão dominante que consegue impor sua visão na formação das políticas públicas por meio do emprego a contento dos recursos disponíveis (dinheiro, estratégias, barganhas, apoios políticos, etc.) (GRISA, 2011).

Deste modo, percebe-se que a restruturação do Estado moderno, como é entendido no contexto atual, pelos rearranjos ocasionados pelas relações sociais e políticas, que sempre estiveram em paralela como as esferas culturais e religiosas, que constituíram e constituem relações ambivalentes com Estado, fatos que são corriqueiros desde a passagem do século XX para o século XXI. A ressignificação das práticas culturais, o desenraizamento dos indivíduos das tradições etc. O que possibilitou o surgimento e múltiplas formas religiosas, bem como múltiplos atores sociais. (GRUMAN, 2005). Assim, os espectros políticos e religiosos se desterritorializam - multiplicando, suas instâncias de influência e conseguintemente, estando em um estado de sobreposição através das fronteiras culturais, políticas, econômicas de várias sociedades 
Religare, ISSN: 19826605, v.16, n.1, agosto de 2019, p.57-84.

contemporâneas ${ }^{13}$. Ou seja, não ocorre a diluição entre a fronteira e os domínios público e privado, de modo que o Estado deixa de ser neutro não mais autônomo perante as identidades particulares, comprovando que a questão, não é mais a separação entre Igreja e Estado, mas a separação entre religião e o poder estatal.

Portanto, criar-se às ambivalências entre a esfera política é esfera religiosa, que transfigura- se a fronteira entre o público e o privado revelando um novo modelo de cidadania, agora vinculado a identidades particulares, universaliza-se o particular, legitimam-se demandas reprimidas, elaboram-se estratégias políticas de modo a definir a natureza da atuação do Estado e suas políticas públicas. (BAPTISTA, 2007; FRESTON, 1993; GRUMAN, 2005, DA MATTA, 1991). Assim, a partir deste contexto social construído, que almejamos compreender o emblemático campo da representação política, ou seja, conceber a representação como um processo que se diferencia no tempo e no espaço, pensar conjuntamente estes diferentes aspectos, que juntos consiste na representação em termos de diferença, o que significa levar em conta a sua temporalidade. (YOUNG, 2000).

\section{A Frente Parlamentar Evangélica no Legislativo Brasileiro}

Acessão de atores e agentes ligados às agremiações religiosas levam para o campo do Poder legislativo brasileiro, não apenas a instauração de uma bancada religiosa e moralista, mas também a transformação do território político-administrativo (de criação de leis e projetos políticos etc.) numa

\footnotetext{
13J.A. BURITY, Religião e Política na fronteira: desinstitucionalização e deslocamento numa relação historicamente polêmica. In: Revista de Estudos da Religião, n.4, 2001.
} 
Religare, ISSN: 19826605, v.16, n.1, agosto de 2019, p.57-84.

extensão do território sagrado da igreja, onde se invocarão o "Deus vivo" e sacralizarão a política.

A Frente Parlamentar Evangélica (FPE) do Congresso Nacional Brasileiro foi instituída na 52ª legislatura (2003-2006), no dia 18 de setembro de 2003, data na qual se comemora o dia nacional de missões evangélicas, em sessão solene proferida pelo então Deputado Federal Pedro Ribeiro (PR/CE). Tal cerimônia fazia deferência às missões religiosas transculturais, mas também era o espaço e o tempo privilegiado para oficializar a instauração da FPE. Que demonstra a força política deste grupo, cuja ação não pode mais ser desconsiderada dos diagnósticos das políticas no país. (TREVISAN, 2013).

Entretanto, no mesmo ano de sua criação a Frente Parlamentar Evangélica, passa por escândalos de denúncias envolvendo corrupção, porém continua-se fortalecendo, defensora de um discurso conservador e de uma moralidade cristã tradicionalista. Na legislatura de 2003 - 2006 a FPE, contava com 75 Deputados Federais e 5 senadores. Já em Novembro de 2015 a FPE conta com 199 Deputados Federais e 4 Senadores. Portanto, ela é vista por seus confrades, como de extrema importância para que possam atuação e influenciar no cenário político. De acordo, com Machado (2012), a instauração da FPE, assim como do Fórum Evangélico Nacional de Ação social e Política ${ }^{14}$, manifesta-se a crescente habilidade dos evangélicos para mobilizar parlamentares para a defesa de interesses suprapartidários. (DUARTE, 2012; TREVISAN, 2013).

Entretanto, a Frente Parlamentar Evangélica, esta organizada da seguinte forma: presidência, coordenação e equipe de assessoria, além de conta com uma sala, onde realiza reuniões semanais para discussão de temas do seu interesse.

\footnotetext{
14 Entidade criada em 2001 pelo Bispo Robson Rodovalho. Sediada em Brasília que busca organizar a comunidade evangélica junto à sociedade civil para demandas políticas de seus interesses e atuação nas Câmaras Municipais e Assembleias Legislativas em todo o país.
} 
Religare, ISSN: 19826605, v.16, n.1, agosto de 2019, p.57-84.

Já os parlamentares são divididos por temáticas, as quais são responsáveis para realizar análises de projetos específicos, elaboração de pareceres e orientação de voto para os demais membros da FPE. Vale salientar que junto com a bancada católica, formam uma base coalização de defesa, que dispõe de força suficiente para impedir que projetos que contrariam os seus interesses não sejam aprovados no Congresso. Por exemplo, temas referentes ao aborto; aos direitos civis de homossexuais, a identidade de gênero etc. (DUARTE, 2012; TREVISAN, 2013).

\section{Figura-02: Cálculo de percentuais e maiorias para fins de processo legislativo ${ }^{15}$}

\begin{tabular}{|c|c|c|c|c|c|}
\hline \multirow{2}{*}{\multicolumn{2}{|c|}{$\underline{\mathrm{N}^{\circ} \text { de membros }}$}} & \multirow{2}{*}{$\begin{array}{c}\text { Maioria } \\
\text { Simples } \\
\text { (ou relativa) } \\
\text { (minima) }\end{array}$} & \multicolumn{3}{|c|}{ Maioria Qualificada } \\
\hline & & & Maioria & Percent. & Percent. \\
\hline CÂMARA & 513 & 129 & 257 & 308 & 171 \\
\hline SENADO & 81 & 21 & 41 & 49 & 27 \\
\hline
\end{tabular}

Fonte: Câmara dos Deputados, 2016.

\footnotetext{
${ }^{15} \mathrm{O}$ art. 45 da Constituição Federal determina que o número total de Deputados, bem como a representação por Estado e pelo Distrito Federal, deve ser estabelecido por lei complementar, proporcionalmente à população, procedendo-se aos ajustes necessários, no ano anterior às eleições, para que nenhuma das unidades da Federação tenha menos de oito ou mais de setenta Deputados. A Lei Complementar no 78, de 30 de dezembro de 1993, estabelece que o número de Deputados não possa ultrapassar quinhentos e treze. A Fundação Instituto Brasileiro de Geografia e Estatística fornece os dados estatísticos para a efetivação do cálculo. Feitos os cálculos, o Tribunal Superior Eleitoral encaminha aos Tribunais Regionais Eleitorais e aos partidos políticos o número de vagas a serem disputadas. Além do número mínimo de representantes, a lei determina que cada Território Federal será representado por quatro Deputados Federais.
} 
Religare, ISSN: 19826605, v.16, n.1, agosto de 2019, p.57-84.

Apesar, de ser articulada por partidos de tendências correntes, a Frente Parlamentar Evangélica, em certos momentos, apresenta estratégia forte de seu poder para consecução de coalizões de defesas conjuntas, bem como a mobilização de pentecostais/neopentecostais na sociedade brasileira. Conforme a figura supracitada, podemos perecer que só os filiados a FPE, consiste em maioria simples nas deliberações e decisões Congresso Nacional.

Porém, quando articulam as coalisões de defesa, conseguem maioria absoluta, por exemplo, articulação com a Frente Parlamentar da Família e Apoio à vida, que conta com 202 Deputados e 26 Senadores. Munidos dessas estratégias, esses parlamentares evangélicos influenciam diretamente nas deliberações da política (DUARTE, 2012; TREVISAN, 2013). Deste modo, a Frente Parlamentar Evangélica acolher parlamentares de diferentes igrejas e de diferentes partidos que advogam em torno de temas em comuns aos seus interesses, corriqueiramente propostas de cunho moral. Ou, quando há interesses institucionais de suas igrejas. Conseguintemente, as pautas que versão sobre a moralidade, muitas vezes extrapolam seus próprios interesses partidários. Porém, a força política de mobilização das igrejas que os apoiam tem se mostrado crescente, de acordo com os dados (Censo 2010) mencionados anteriormente.

Figura-03: Frente Parlamentar Evangélica (FPE) Câmara dos Deputados 2015. 


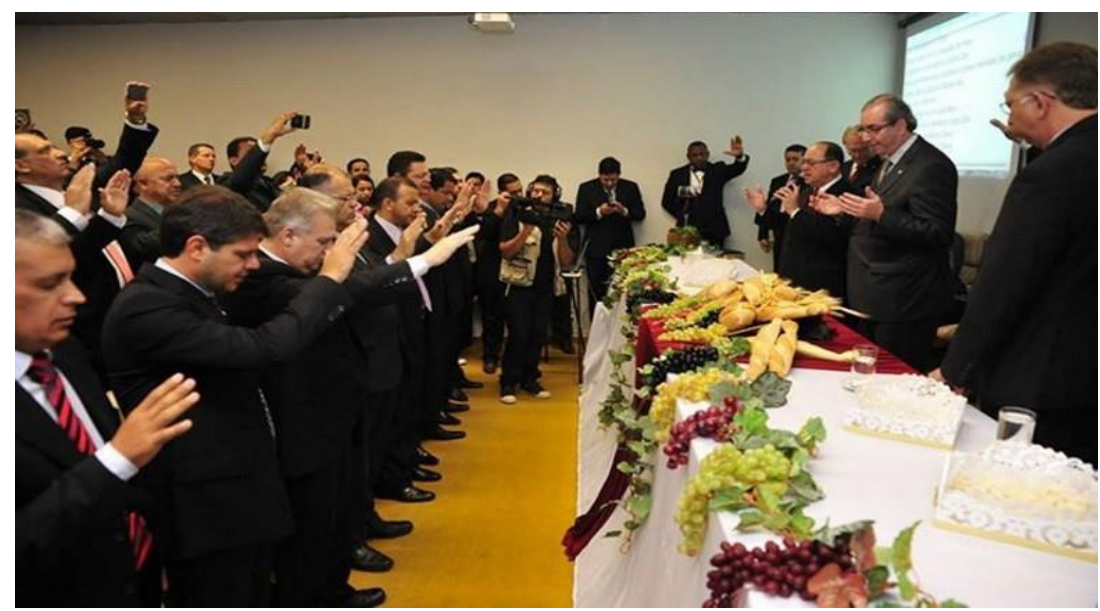

Fonte: Acervo, Helder Lima, da RBA publicado 25/04/2015.

Por outro lado, analisando a figura supracitada, quanto é forte o poder hegemônico desta frente no congresso nacional (Deputado Federal e Pastor Eduardo Cunha, conduz culto evangélico na Câmara dos deputados, Ferindo artigo 19 da Constituição Federal), tais fatos, suscitam o debate entorno da à legitimidade ou pertinência da participação religiosa na esfera pública tem gerado diferentes debates e opiniões entre atores/grupos religiosos e seculares.

Vale salientar, que no Brasil, os grupos religiosos já perceberam a importância da utilização de argumentos jurídicos em meio aos seus argumentos religiosos, para serem aceitos e legítimos em um "Estado Democrático Laico". Entretanto e expressiva a presença de pastores e outras lideranças evangélicas no parlamento, conduzem os movimentos da Frente Parlamentar Evangélica e suas articulações dentro e fora do Congresso Nacional. (TREVISAN, 2013).

Todavia, na modernidade, a religião transvertida em seus parlamentares moralistas, continua a ocupar os espaços de deliberação pública, governando credos, determinando valores, reivindicando lugar no cerne da elaboração de políticas. Portanto, no caso brasileiro, a práxis religiosa ocupa o mundo, já o político, gesta as intenções baseadas em uma missão. Porém se a igreja 
Religare, ISSN: 19826605, v.16, n.1, agosto de 2019, p.57-84.

congrega-se no mundo, ela precisa anunciar as "boas novas", e propiciar a sociedade dos bons costumes. Nessa lógica, o sagrado e profano se mesclam (assim como Estado e Igreja, politica e religião), na vivencia do campo politico brasileiro, em decorrência do ativismo destes religiosos. Já, a metáfora "ser um missionário" no Congresso Nacional (DUARTE, 2012). Assim, tal trocadinho linguístico, versa em um o primeiro momento, no compromisso, do fiel com a obra de Deus, por meio da realização de cultos etc. $\mathrm{O}$ segundo consiste que o exercício da política, pelos fieis, invertidos em cargos públicos deve se pautar pela luta em prol das "bandeiras do Evangelho". Nesse sentido, estar no mundo e na política, aceita que os "escolhidos de Deus verbalizem o religioso, agenciando efeitos na política" e transformando a sociedade. (DUARTE, 2012; TREVISAN, 2013).

\section{Considerações Finais}

Este trabalho procurou lançar luz sobre alguns traços do trade policymaking a partir das inter-relações que se estabelecem entre Estado e Religião e a formação de coalizões de defesa caracterizadas por disputas, alianças e filiações que cristalizam diferentes facções dentro de um determinado subsistema de políticas públicas sob a égide de visões da política que dão fôlego à coalizão. Tendo como pressuposto que a política e a religião neopentecostal, cria-se coalisões de defesas em prol de interesse religiosos e moralistas, em especial as negociações feitas por esta bancada evangélica desde o período de redemocratização.

A coalizão de defesa mostrou-se um lócus privilegiado nesse sentido, permitindo fazer valer as visões de mundo dos atores neopentecostais no bojo das negociações do cenário politico brasileiro, desempenhando, 
Religare, ISSN: 19826605, v.16, n.1, agosto de 2019, p.57-84.

simultaneamente, um papel importante na articulação entre diferentes ideias e interesses, entre os diferentes segmentos da sociedade civil e do setor privado.

Vale salientar, que as coalizões de defesas praticadas por estes grupos evangélicos atrelados a estrutura política do legislativo brasileiro, estende-se desde o congresso constituinte e da eleição que elegeu Fernando Collor (198689) a Presidência da República, fato relevante é que as pautas dessas coalizões de parlamentares pentecostais consistiam na defesa das liberdades religiosas; proteção da família tradicional; politização de questões morais e um discurso anti-PT. (FRESTON, 1993).

Assim, perceber-se que estas articulações pautadas nestes critérios fortemente conservadores se alastraram pelas demais legislaturas, na recente democracia brasileira. Entretanto, na legislatura de 2003-2006, FPE se fortaleceu, conquistando apoio, legitimidade e, consequentemente, espaço político. No entanto, tal força ficou perceptiva com a eleição do Deputado Federal pastor Marco Feliciano para a presidência da Comissão de Direitos Humanos e Minorias da Câmara dos Deputados, em 7 de março de 2013, bem como à sua defesa do projeto sobre a "cura gay"16, além de seus pronunciamentos e declarações homofóbicas ${ }^{17}$ e machistas ${ }^{18}$ e racista, tais afirmações repercutiram

\footnotetext{
16 Fontes: http://www1.folha.uol.com.br/poder/2013/06/1298045-marco-antonio-teixeiraprojetopolemico-foi-aprovado-a-sombra-de-protestos.shtml; http://www1.folha.uol.com. br/cotidiano/2013/06/1299397-protesto-contra-cura-gay-reune-1000-em-sao-paulo.shtml; http://www1.folha.uol.com.br/poder/2013/07/1305310-lideres-da-bancada-evangelicasearticulam-para-apresentar-novo-projeto-da-cura-gay.shtml.

17 Fontes: http://oglobo.globo.com/pais/pastor-marco-feliciano-reu-por-homofobiaestelionato7778274; http://veja.abril.com.br/noticia/brasil/marco-feliciano-outrodeputado-contra-gays-enegros; http://oglobo.globo.com/politica/deputado-federal-marcofeliciano-faz-coro-asdeclaracoes-de-bolsonaro-ataca-negros-homossexuais-2802944

1818 Fonte: http://oglobo.globo.com/pais/marco-feliciano-diz-que-direitos-dasmulheresatingem-familia-7889259
} 
Religare, ISSN: 19826605, v.16, n.1, agosto de 2019, p.57-84.

e ouve vários protestos ${ }^{19}$ por todo o país, tais desdobramentos, causaram desgastes político a Frente Parlamentar Evangélica.

No entanto, os parlamentares e outras organizações ligadas às causas dos direitos humanos (Feministas, homossexuais, estudantes, artistas e diversos outros segmentos sociais) articularam uma onda de manifestações na tentativa de criar uma coalização de oposição, porém sem êxito, pois o ocorreu a sua nomeação e posse do mesmo. O episódio supracitado possibilitou visibilidade aos movimentos contrários, aos interesses dos evangélicos, especialmente o movimento feminista e LGBT.

Outro momento importante a ser destacado é eleição para presidência da câmara dos Deputados, do Pastor é então Deputado Eduardo Cunha (PMDBRJ), a discussão sobre a eleição em primeiro turno com 267 votos, maioria absoluta no Congresso Nacional, com essa vitória nas eleição, torna-se o segundo na linha de sucessão da Presidente da República, ou seja, aqui se expressa o poder adquirido pela bancada evangélica no legislativo.

Portanto, as articulações arquitetadas pela bancada evangélica, no legislativo brasileiro, tem sido marcado por um forte tradicionalismo moral da Frente Parlamentar Evangélica, que tem a missão de atuação na defesa da família e da moral cristã, sendo contra a plataforma dos movimentos feministas; da identidade de gênero, dos homossexuais e dos grupos de direitos humanos, valendo-se de alianças até mesmo com parlamentares católicos, fomentando um discurso moralístico, anticorrupção etc. Tais acordos e barganhas políticas, historicamente impensáveis no campo eclesiástico.

\footnotetext{
19 Fonte: http://zerohora.clicrbs.com.br/rs/politica/noticia/2013/03/marco-felicianoemitedeclaracoes-machistas-e-causa-indignacao-nas-redes-sociais-4080604.html; http://oglobo. globo.com/pais/entidades-partidos-reagem-eleicao-de-marco-feliciano-7770263; $\quad$ http:// blogay.blogfolha.uol.com.br/2013/03/21/divulgado-video-feliciano-nao-me-representa/; http://www1.folha.uol.com.br/poder/1247667-pelo-segundo-final-de-semana-feliciano-ealvo-deprotestos.shtml.
} 
Religare, ISSN: 19826605, v.16, n.1, agosto de 2019, p.57-84.

Tal discurso tornou-se máxima, junto aos protestos anticorrupção que tomaram as ruas do país, no ano de 2015, fomentado por uma direita conservadora e uma elite privilegiada, e uma massa de manobra significativa, eclodiram muitos aspectos das causas defendidas pela bancada evangélica em 1986, agora revertida por um discurso neoliberal em defesa da sociedade brasileira.

Essa nova, tática de coalisão, tem um agravo que atinge não só evangélicos, mas também católicos e outros grupos sociais mais conservadores, que não são ligados à religião formando assim uma coalisão de defesa em prol da moralidade e dos bons costumes, quiçá na defesa de um projeto de embrião de "Estado Neopentecostal".

\section{Referências}

BAPTISTA, Saulo de Tarso Cerqueira. Fundamentalismo como ideologia: a Igreja Batista Regular no Brasil. Trabalho de conclusão de curso. Bacharelado e Licenciatura em Ciências Sociais - Universidade Federal do Pará, Belém, 2000, $136 \mathrm{p}$

BOHN, Simone. Evangélicos no Brasil. Perfil socioeconômico, afinidades ideológicas e determinantes do comportamento eleitoral. Opinião Pública,, v. X, n. 2, Campinas, out. 2004, p. 288-338.

BAPTISTA, Saulo de Tarso Cerqueira. "Fora do mundo", dentro da política: Identidade e "missão parlamentar" da Assembléia de Deus em Belém. Dissertação de Mestrado em Sociologia - Universidade Federal do Pará, Belém, 2002.

BAQUERO, Marcello (org.). Reinventando a sociedade na América Latina: cultura política, gênero, exclusão e capital social. Porto Alegre/Brasília: UFRGS/Conselho Nacional dos Direitos da Mulher (CNDM), 2001.

DURTE, T, S. A participação da frente parlamentar evangélica no legislativo Brasileiro: ação política e (in) vocação, religiosa Ciencias Sociales y Religión/Ciências Sociais e Religião, Porto Alegre, ano 14, n. 17, p. 53-76, Jul./Dic. 2012

HOWLETT, M; RAMESH, M; PERL, A. Políticas públicas: seus ciclos e subsistemas: uma abordagem integral. Rio de Janeiro: Elsevier, 2013. 
Religare, ISSN: 19826605, v.16, n.1, agosto de 2019, p.57-84.

FRESTON, Paul. Entre o pentecostalismo e o declínio do denominacionalismo: o futuro das igrejas históricas no Brasil. In: CAMPOS, Leonildo Silveira; GUTIÉRREZ, Benjamin F. (org.). Na força do Espírito: os pentecostais na América Latina: um desafio às igrejas históricas. São Paulo: AIPRAL/ Pendão Real, 1996.

FRESTON, Paul. Evangelicals and Politics in Asia, Africa and America Latina. Cambridge, UK: Cambridge University Press, 2001.

FRESTON, Paul. Evangélicos na política brasileira. Religião e Sociedade, Rio de Janeiro: ISER, no 16/1-2, 1992.

FRESTON, Paul. Fé bíblica e crise brasileira. São Paulo: ABU, 1992

FRESTON, Paul. Protestantes e política no Brasil: da Constituinte ao impeachment. Tese de doutorado em Sociologia. Departamento de Ciências Sociais do Instituto de Filosofia e Ciências Humanas da Universidade Estadual de Campinas, 1993..

GURZA LAVALLE, Adrián. Vida pública e identidade nacional: leituras brasileiras. São Paulo: Globo, 2004.

GRISA, Cátia. As ideias na produção de políticas públicas: contribuições da abordagem cognitiva. In: Bonnal, P.; Leite, S.P. (Orgs.). Análise comparada de políticas agrícolas: uma agenda em transformação. Rio de Janeiro: Mauad, 2011.

LOWI, Theodor. "American Business, Public Policy, Case Studies and Political Theory", World Politics, 16: 677-715. 1964

LOWI, Theodor. "Four Systems of Policy, Politics, and Choice". Public Administration Review, 32: 298-310. 1972.

LIMA, Maria Regina Soares de. Instituições democráticas e política exterior. Contexto Internacional, v. 22, n. 2, 2000.

Relações Internacionais e políticas públicas: a contribuição da análise de política externa. In: MARQUES, Eduardo; FARIA, Carlos Aurélio P. de (Orgs.). A política pública como campo multidisciplinar. São Paulo: Editora Unesp; Rio de Janeiro: Editora Fiocruz, 2013.

MARQUES, Eduardo e FARIA, Carlos Aurélio. A política pública como campo multidisciplinar. São Paulo: Editora Unesp; Rio De Janeiro: Editora Fiocruz, 2013. MELO, Marcus A. Estado, governo e políticas públicas. In: Sérgio Miceli (org.). O que ler na ciência social brasileira (1970-1995). São Paulo: Sumaré, 1999.

MARIANO, R. Efeitos da secularização do Estado, do pluralismo e do mercado religioso sobre as igrejas pentecostais. Civitas - Porto Alegre, v 3,no 1, jun,2003.

MACHADO, Maria das Dores Campos. Evangelicals and Politics in Brazil: the case of Rio de Janeiro. Religion, State \& Society, v. 40, n. 1, mar. 2012.

MARIANO, Ricardo. Noepentecostais: sociologia do novo pentecostalismo no Brasil. São Paulo: Loyola, v. 2, 1999.

RODRIGUES, Marta Maria A. Políticas Públicas. São Paulo: Publifolha, 2013 (Folha Explica). 
SABATIER, Paul. Advocacy coalition framework (ACF). In: BAUSSAGUET, L. et al. (Org.). Dictionnaire de politiques publiques. 2 ed. Paris : Presses de Sciences Po, 2006, p. 4251.

SOUZA, Celina. Políticas Públicas: uma revisão da literatura. Sociologias, Porto Alegre, ano 8, n 16, jul/dez, 2006

SORJ, Bernardo. A nova sociedade brasileira. 2. ed. Rio de Janeiro: Jorge Zahar, 2001, p. 11-12

PIERUCCI, Antônio Flávio. Representantes de Deus em Brasília: a bancada evangélica na Constituinte. In: PIERUCCI, A. F.; PRANDI, R. A realidade social das religiões no Brasil. São Paulo: Ed. Hucitec, 1996.

PETERS, B. G. (1986) American Public Policy. Chatham, N.J.: Chatham House.

B. G (1995) The Politics of Bureaucracy. White Plains: Longman Publishers

B. G. (1998) "Review: Understanding Governance: Policy Networks, Governance, Reflexivity and Accountability by R. W. Rhodes", Public Administration 76: 408-509.

TRIVISAN, J. A Frente Parlamentar Evangélica: Força política no estado laico brasileiro. Numen: revista de estudos e pesquisa da religião, Juiz de Fora, v. 16, n. 1, p. 581-609.

Recebido em 15/09/2018.

Aprovado em 11/07/2019. 